\title{
Personalized Learning Path of a Web-based Learning System
}

\author{
Andharini Dwi C \\ Informatics Engineering \\ Trunojoyo University \\ Indonesia
}

\author{
Ari Basuki \\ Industrial Engineering \\ Trunojoyo University \\ Indonesia
}

\begin{abstract}
Recently, the growth of web learning system has stimulated the research on adaptive learning opportunity which is suitable to students' need and their preferences. One of those adaptation techniques is adaptive course material sequencing, in which the prerequisite for adaptive material sequencing is recognizing the students' knowledge level. The aim of this paper is to provide web learning system with relatively simple adaptive course material sequencing based on students' knowledge level and students' feedback of material difficulty level. Students' knowledge level is obtained from the analysis of pre-test result, while students' feedback is acquired through questionnaire after they finish a learning unit. After students give feedback, the system then modify the difficulty level of the corresponding learning unit to update courseware material sequencing. Findings of the experimental study showed that the students' effectiveness and achievements in personalized learning mode were higher, in comparison to the non-personalized learning mode.
\end{abstract}

\section{General Terms}

Adaptive Web Based Learning System

\section{Keywords}

English learning, Personalized learning path, web-based learning

\section{INTRODUCTION}

Today, the use of web-based education systems or e-learning has grown significantly, driven by the fact that students and teachers are not required to be at specific location in the same time, and learning process can be done with individual pace and at anywhere and anytime. Therefore, web based e-learning systems has been a hot topic during the recent years. Since online course materials resources grow rapidly that the problem of how to help learners get appropriate learning materials to fit their learning needs has become a popular research subject in the area of personalized web learning system. To recommend appropriate learning material for a certain students, we should consider the students characteristic, such as : learning modality, cognitive style and competency[1]. However, it is a challenge to develop e-learning systems that is suitable for the different needs of students, so the students can learn efficiently while keeping up with the pace of learning.

Research on adaptive learning system to meet students' need and their preferences, which is beneficial for web-based learning, has become popular recently. Adaptive learning system provides an alternative to the traditional system which is ignore personal characteristic of students [2]. Several intelligent proposed systems have been developed with different variables for adaptive web based learning system. These variables were the cognitive traits [3;4], multiple intelligences [5], cognitive styles [6], and learning behavior [7]. However, these systems neglect the importance of student's ability and student's feedback when implementing personalized mechanisms.

In the approach presented in this paper, students' knowledge level and students' feedback are used as valuable information to represent student's current state and modify the difficulty level of each course material, in order to update the courseware material sequence based on students' perception. Courseware material sequencing aims to provide an optimal learning path to individual student since every student has different prior background knowledge. The main objectives of this research are to protect student from cognitive overload and disorientation by supporting them to find the most relevant learning unit and path in web based e-learning. Therefore, considering student's ability and feedback can promote personalized learning performance.

\section{THE PROPOSED PERSONALIZED LEARNING SYSTEM}

This section describes the novel system architecture, components and the personalized mechanism implemented for the application. First an overview of the system architecture and components is presented in Section 2.1 and then followed by section 2.2 which describes personalized mechanism and system operation.

\subsection{System Architecture \& Component}

In this personalized learning application, we propose 2 agents of system namely: interface agent, and personalized agent. Interface agent selects which learning mode, non-personalized learning mode or personalized learning mode that will be used by students. If a student is granted for non-personalized learning mode, then the student may choose any course materials to learn by himself after doing pre-test. In other hand, when student is granted for personalized learning mode, after doing pre-test, student should learn the recommended course materials which are generated by this application. The sequence of recommended course materials, called recommendation learning path, is built by personalization agent based on the analysis of pre-test result. Furthermore, the system operation and personalized mechanism are shown in Figure 1. 


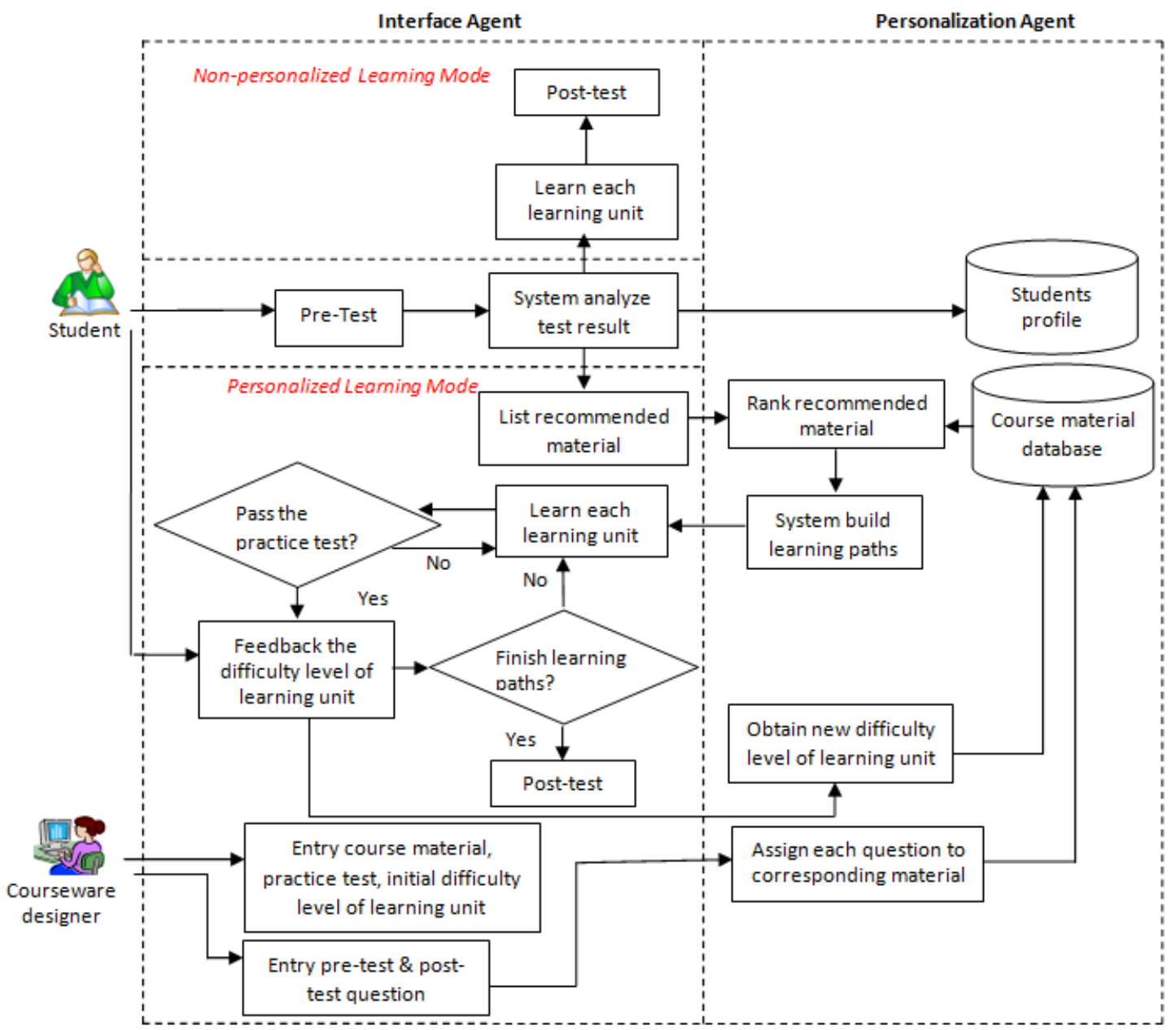

Figure 1. Overview personalization e-learning system

\subsection{Interface Agent}

Interface agent is responsible for selecting students and their learning mode, non-personalized learning mode or personalized learning mode. For both learning modes, students should take pre-test so that the system acknowledge students' initial ability. Afterward, interface agent will analyze the test result and store the students score into database.

Next, there is a different path for non-personalized learning mode and personalized learning mode. As abovementioned, in non-personalized learning mode, the student may take any course materials after doing pre-test. Nevertheless, in personalized learning mode, the student should learn about recommended course materials which is generated by interface agent. When students can answer correctly the corresponding test questions of some course materials, this indicates that the students have acquired the course materials. Otherwise, if students' answer is wrong, the system will set the corresponding course materials as recommended learning unit. Then, the list of recommended course materials will be ranked by personalization agent.

Furthermore, interface agent is also handle feedback about the difficulty level of learning unit that has been learned by students. This feedback is given to students after they have succesfully finish a learning unit. Only one brief question in this questionnaire: "What do you think about the difficulty level of this learning unit?". This question requires student to select from a 5-level degree scale: "very hard", "hard", "moderate", "easy" and "very easy", which indicate -2, - - $0,1,2$ respectively. This feedback is needed to update the difficulty level of each learning unit, which is handled by personalization agent.

The system in the interface agent is also responsible to manage the course material of learning unit, the practice test, and pretest/post-test. Practice test contains 5 types of question, namely : true/false question, completion question, multiple choice, and further exercise. While the type of questions in pre-test/post-test is only multiple choice. The types of practice test, pre-test and post-test question are shown in course ontology, Figure 2.

\subsection{Personalization Agent}

Personalization agent deals with the recommendation and learning path which is built for individualized student. In general, if the course material is too difficult to understand by students, then it may frustrate them. On the contrary, excessively easy course materials can cause students to lack any sense of challenges and thus waste of time. Therefore, providing appropriate course materials to students is important for Web-based learning systems.

As the aforementioned, interface agent makes list of recommended course material based on students' pre-test result. Then, the list is ranked by personalization agent based on difficulty level of each learning unit. In this research, each learning unit has its own difficulty level. Initially, the difficulty 
level of each learning unit is assigned by courseware designer New difficulty level of a learning unit is a linear combination of the course difficulty as defined by courseware designers and assessed by students with adjustable weight assigned to each. After the students give feedback, the system will modify the difficulty level of the corresponding learning unit in course material database using collaborative voting (Eq. 1). Suppose that initial_ $d_{i}$ is the initial difficulty level of chapter $i$ which is defined by courseware designer and voting $\mathrm{d}_{\mathrm{i}}$ is average of difficulty level based on student questionnaire, then new_ $d_{i}$ can be acquired using Eq. (2).

voting_d $d_{i}=\sum_{j=-2}^{2} \frac{j * n_{j i}}{n_{i}}$

$n e w_{-} d_{i}=\left(w *\right.$ initial $\left._{d_{i}}\right)+\left((1-w) *\right.$ voting $\left._{-} d_{i}\right)$

where $\mathrm{j}$ denotes the difficulty level obtained by student's questionnaire, $n_{j i}$ indicates the number of student that rate the $i^{\text {th }}$ learning unit belonging to $\mathrm{j}$-difficult level and $n_{i}$ reveals the number of students that rate learning unit. Afterwards, personalization agent assigns new_ $\mathrm{d}_{\mathrm{i}}$ as new difficulty level of $\mathrm{i}^{\text {th }}$ learning unit and ranks the learning unit based on new obtained difficulty level.

Once students are given sequence of recommended materials, called learning path, they should learn material and pass its practice test. Students should achieve minimum score to be considered as successfully pass the corresponding learning unit.

\section{APPLICATION OF AN ENGLISH LEARNING SYSTEM}

The course ontology used in this English language learning system is represented by Figure 2. This learning content consists of 29 units and a number of practice tests. Each unit has its own difficulty level which is obtained through collaborative voting by courseware designer and students.

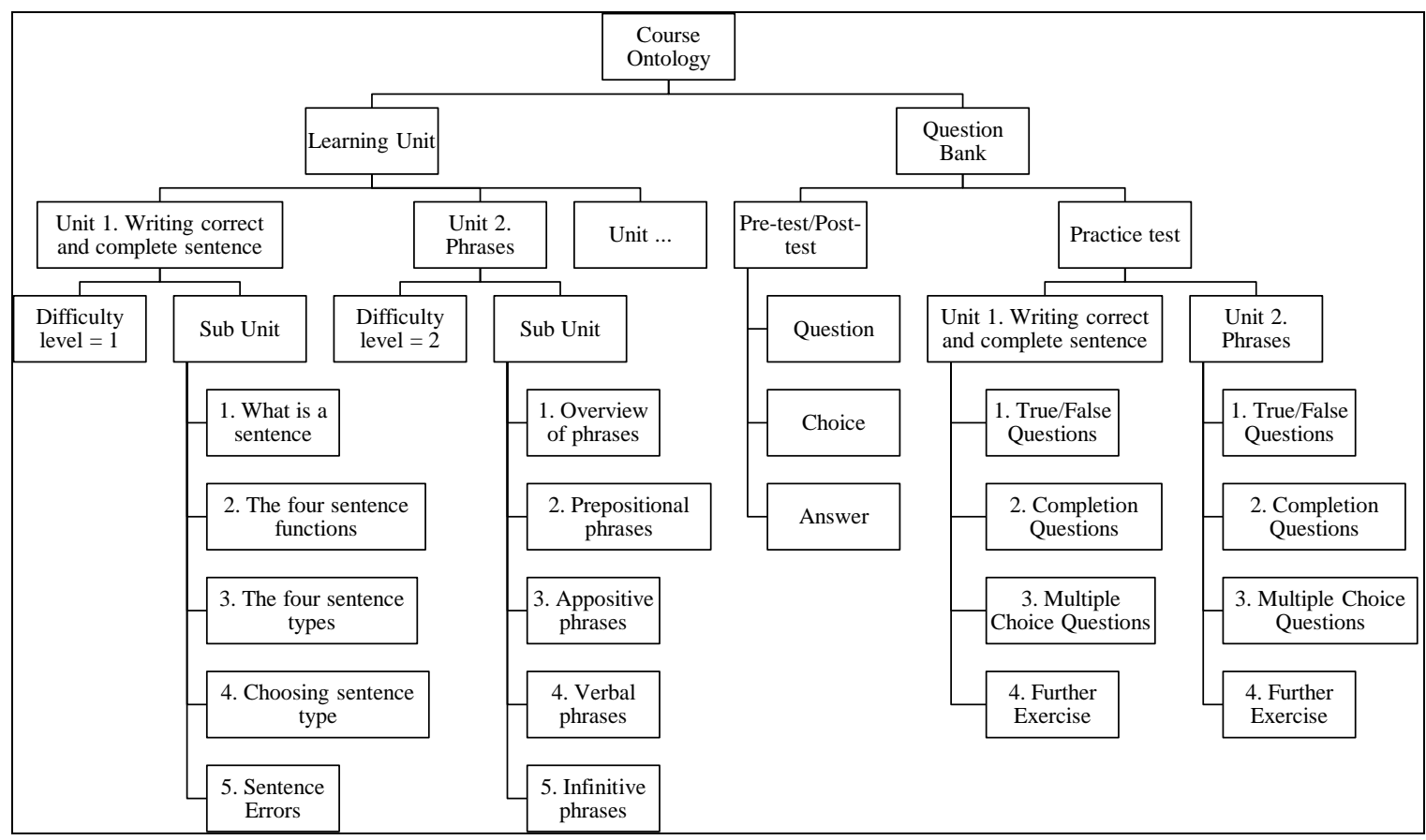

Figure 2. Course ontology

Courseware designer may input the course material and set the difficulty level each material at the beginning, before this application is used by students. Figure 3 and Figure 4 represent the input screen of course material and input screen of question, respectively.

As presented in Figure 1, the first step of our proposed work is the student takes a pre-test. Afterward, the interface agent analyzes the test result and makes a list of learning unit that should be studied by the students. This list of recommended learning unit, called learning path, is sorted ascending based on its difficulty level. The learning path is shown in Figure 5.

When the students have learned a recommended learning unit, then they have to take practice test as displayed in Figure 6 and satisfy the minimum score before continuing to learn the next learning units. The students may continue to start the next learning units if their practice test score under $70 \%$ correct answer. This step then should be repeated again until the students pass the entire recommended learning units. Finally, the students may take post-test to acknowledge their new ability.

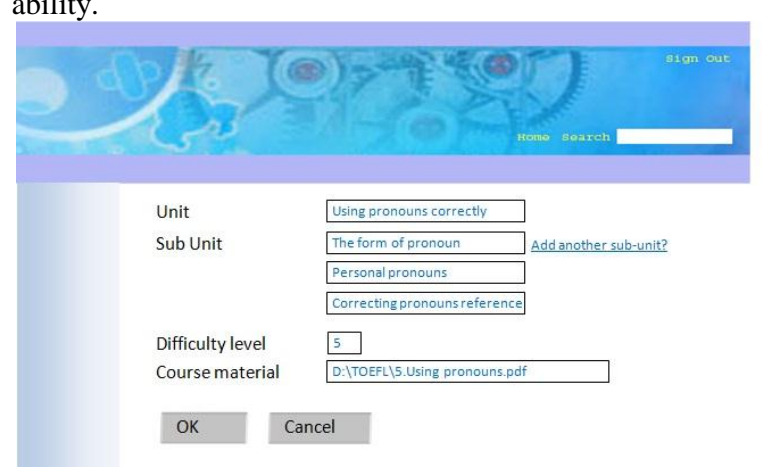

Figure 3. Input screen of learning unit and course material 


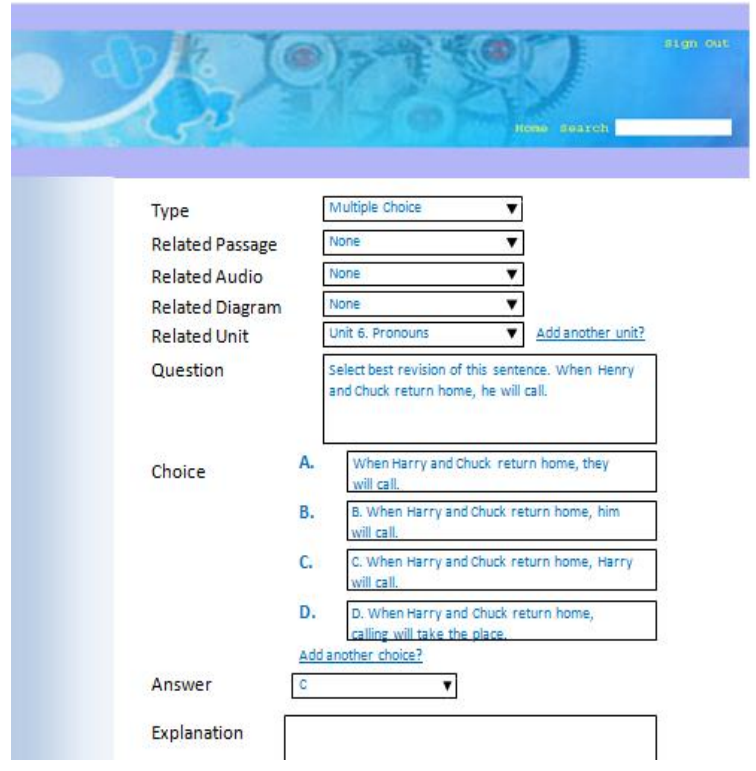

Figure 4. Input screen of practice test question

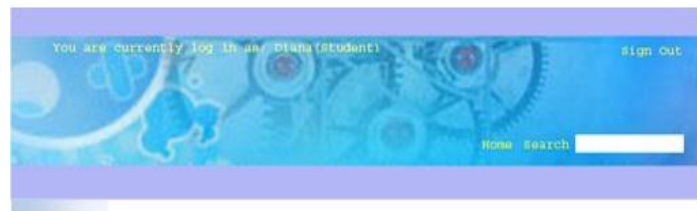

You should learn this recommended unit(s) to improve your English language skill. Each unit have sub-unit(s). To pass a learning unit, you should answer mini test and practice test which is provided at the end of each sub-unit and learning unit, respectively. Should you meet the minimum score, you can start to learn next recommended learning unit.

Unit 3. Parts of Speech

Unit 5. Using pronouns correctly

Unit 6. Using verbs correctly

Unit 10. Most Common Grammar and Usage Errors

Unit 11. Most common Sentence Errors

Unit 12. Most Common Punctuation Errors

Unit 13. Most Common Soflling Errors

Unit 15. Sentence coordination and Subordination

Figure 5. Recommended learning path that is obtained after students take a pre-test

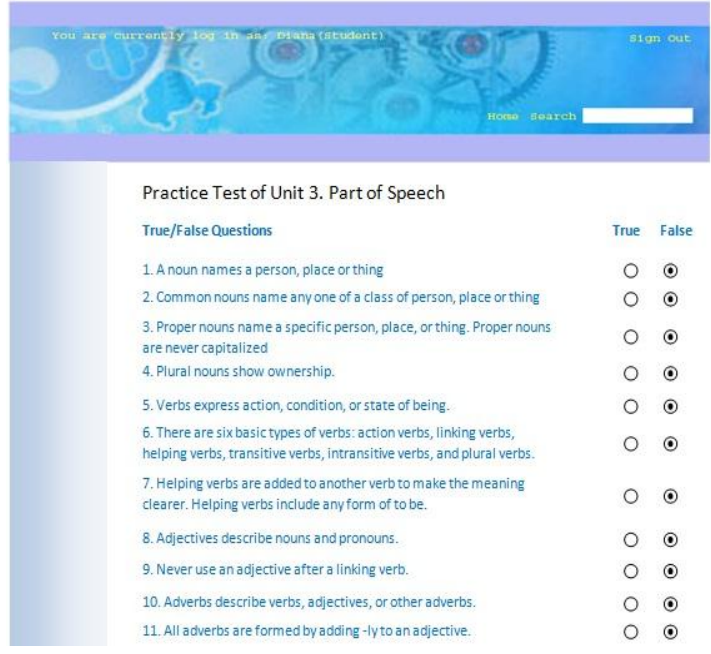

Figure 6. Practice test of a recommended learning unit

\section{EXPERIMENTAL RESULT}

\subsection{Experimental Design}

To evaluate the effectiveness of the proposed personalized learning system, we conducted an experiment with the English language learning system described in section X. Experiments were conducted with university students enrolled in English Language Learning community. There were 97 participants selected who were willing to join in testing this system. The demographic information about participants is listed in Table 1.

Table 1. Demographic information about participants

\begin{tabular}{lll}
\hline Characteristic & Control Group & Treatment Group \\
\hline 1st year & $16(16.49 \%)$ & $19(19.59 \%)$ \\
2nd year & $18(18.56 \%)$ & $22(22.68 \%)$ \\
3rd year & $12(12.37 \%)$ & $10(10.31 \%)$ \\
\hline Total & $\mathbf{4 6}$ & $\mathbf{5 1}$ \\
\hline
\end{tabular}

Among 97 university students, 46 students were served as the control group to perform the non-personalized learning mode, while the rest, 51 students, were served as the treatment group to perform the proposed personalized learning mode. In this experiment, both groups perform pre-test, learning process and post-test simultaneously for comparing their learning performance.

In the beginning, we have explained to the participants about the procedures of our system. Once the participants logged in to the system, they should follow three learning stages, namely : pre-test process, learning process and post-test process. The participants used this system for a week and at their own time and pace of learning.

\subsection{Experimental Analysis}

Table 2 shows the learning performance comparison of both non-personalized learning mode and personalized learning mode. The result reveals that $50,98 \%$ of students using personalized mode have progressive learning scores, while the percentage of students using non-personalized learning mode is only $41,3 \%$.

Table 2. Learning performance promotion comparison of both learning modes

\begin{tabular}{|l|c|c|}
\hline \multicolumn{1}{|c|}{ Variables } & $\begin{array}{c}\text { Non- } \\
\text { personalized } \\
\text { learning mode }\end{array}$ & $\begin{array}{c}\text { Personalized } \\
\text { learning } \\
\text { mode }\end{array}$ \\
\hline \# students & 46 & 51 \\
\hline $\begin{array}{l}\text { \# students with } \\
\text { progressive score }\end{array}$ & $19(41,3 \%)$ & $26(50,98 \%)$ \\
\hline $\begin{array}{l}\text { \# students with } \\
\text { retrogressive score }\end{array}$ & $12(26,09 \%)$ & $13(25,5 \%)$ \\
\hline $\begin{array}{l}\text { \# students with } \\
\text { constant score }\end{array}$ & $15(32,61 \%)$ & $12(23,5 \%)$ \\
\hline
\end{tabular}

Next, we utilize statistical method to analyze the learning performance data. We use Paired-samples T-test to find whether both learning modes provide benefits in terms of learning performance promotion based on pre-test and post-test scores. In this study, we want to find out the learning performance promotion of the non-personalized learning mode, personalized learning mode and also the learning performance promotion of the students who have the same pre-test score in both the learning modes. All those three cases are respectively discussed as follows:

Case 1: The paired-samples T-test for assessing the learning performance promotion of the non-personalized learning mode. 
The statistical information for the paired-samples T-test of the control group is listed in Table 3. Based on its goal, in this case we have two research hypotheses which is described below:

$\mathrm{H}_{0}$ Case 1: Suppose the students using non-personalized learning mode have the same mean score in both pre-test and post test.

$\mathrm{H}_{1}$ Case 1: Suppose the students using non-personalized learning mode do not have the same mean score in both pre-test and post-test.

Table 3. Statistical information for the matched-pair T-test of non-personalized learning mode

\begin{tabular}{|c|c|c|c|c|c|}
\hline \multicolumn{2}{|c|}{} & Mean & N & $\begin{array}{c}\text { Std. } \\
\text { Deviation }\end{array}$ & $\begin{array}{c}\text { Std. } \\
\text { Error } \\
\text { Mean }\end{array}$ \\
\hline $\begin{array}{c}\text { Pair } \\
1\end{array}$ & Pre_test_Score & 72,53 & 46 & 3,358 & 0,495 \\
\cline { 2 - 6 } & Post_test_Score & 72,30 & 46 & 4,131 & 0,609 \\
\hline
\end{tabular}

The result of paired-samples T-test in Table 4 shows that the research hypotheses $\mathrm{HO}$ is satisfied with significant level $\alpha=0.05$ and $P=0.519>0.05$. Therefore, we can conclude that non-personalized learning mode have no benefits in terms of learning performance promotion. Furthermore, information in Table 3 shows that the mean score of the students' post-test is zlower 0,23 points from their pre-test score.

Table 4. Result of paired-samples T-test of non-personalized learning mode

\begin{tabular}{|c|c|c|c|c|c|c|c|c|c|}
\hline & & \multicolumn{5}{|c|}{ Paired Differences } & \multirow{3}{*}{$\mathrm{t}$} & \multirow{3}{*}{ df } & \multirow{3}{*}{$\begin{array}{l}\text { Sig. (2- } \\
\text { tailed) }\end{array}$} \\
\hline & & \multirow[t]{2}{*}{ Mean } & \multirow[t]{2}{*}{$\begin{array}{c}\text { Std. } \\
\text { Deviation }\end{array}$} & \multirow[t]{2}{*}{$\begin{array}{l}\text { Std. Error } \\
\text { Mean }\end{array}$} & \multicolumn{2}{|c|}{$\begin{array}{l}95 \% \text { Confidence } \\
\text { Interval of the } \\
\text { Difference }\end{array}$} & & & \\
\hline & & & & & Lower & Upper & & & \\
\hline $\begin{array}{c}\text { Pair } \\
1\end{array}$ & $\begin{array}{l}\text { Pre_test_Score - } \\
\text { Post_test_Score }\end{array}$ & 0,239 & 2,496 & 0,368 & $-0,50211$ & 0,9803 & 0,650 & 45 & 0,519 \\
\hline
\end{tabular}

Case 2: The paired-samples T-test for assessing the learning performance promotion of the personalized learning mode. The statistical information for the paired-samples T-test of the treatment group is listed in Table 5. In this case, we want to determine whether the two means of pre-test and post-test score in personalized learning mode were significantly different. Therefore, we have two research hypotheses which are described below:

$\mathrm{H}_{0}$ Case 2: Suppose the students using personalized learning mode have the same mean score in both pre-test and post test.
$\mathrm{H}_{1}$ Case 2: Suppose the students using personalized learning mode do not have the same mean score in both pre-test and post-test.

Table 5. Statistical information for the paired-samples $T$ test of personalized learning mode

\begin{tabular}{|c|l|r|r|r|c|}
\hline \multicolumn{2}{|c|}{} & Mean & N & $\begin{array}{c}\text { Std. } \\
\text { Deviation }\end{array}$ & $\begin{array}{c}\text { Std. } \\
\text { Error } \\
\text { Mean }\end{array}$ \\
\hline $\begin{array}{c}\text { Pair } \\
1\end{array}$ & Pre_test_Score & 71,314 & 51 & 2,796 & 0,392 \\
\cline { 2 - 6 } & Post_test_Score & 73,098 & 51 & 4,993 & 0,699 \\
\hline
\end{tabular}

Table 6. Result of paired-samples T-test of personalized learning mode

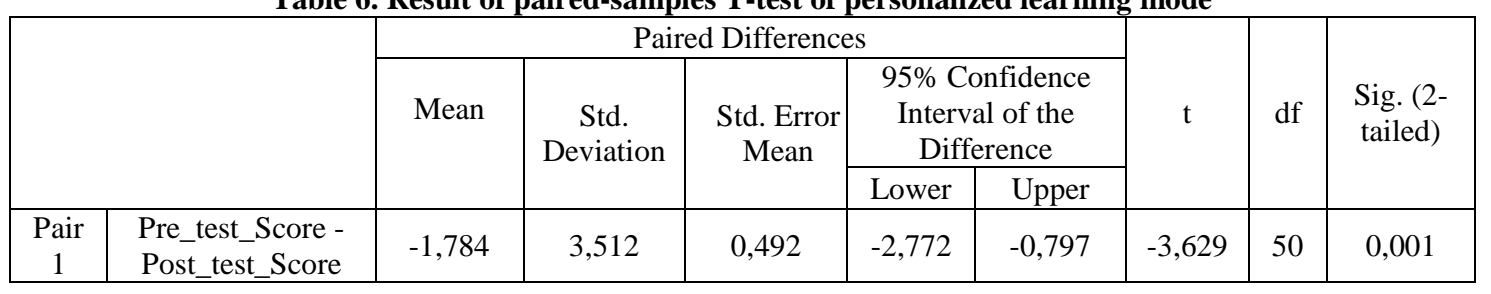

The result of paired-samples T-test in Table 6 shows that the research hypotheses $\mathrm{H} 1$ is satisfied with significant level $\alpha=0.05$ and $P=0.001<0.05$. This mean to say that personalized learning mode provides benefits in terms of learning performance promotion. Based on the information in Table 5, we can acknowledge that the mean score of the students' post-test is higher 0,307 points from their pre-test score.

Case 3: The paired-samples T-test for assessing the learning performance promotion of students with the same pre-test score from both learning mode. The statistical information for the paired-samples T-test of students who have the same pre-test score is listed in Table 7. To compare the learning performance from both learning mode, in this case we have two research hypotheses which are described below:
$\mathrm{H}_{0}$ Case 3: Suppose the students using non-personalized learning mode have the same mean score in post-test with students using personalized learning mode.

$\mathrm{H}_{1}$ Case 3: Suppose the students using non-personalized learning mode do not have the same mean score in post-test with students using personalized learning mode.

Table 8 shows the results of paired-samples T-test of Case 3, that point out that the research hypotheses $\mathrm{H} 1$ is satisfied with significant level $\alpha=0,05$ and $\mathrm{P}=0,000<0,05$. These results suggest that the learning performance can indeed be enhanced further through personalized learning mode. In addition, information in Table 7 reveals that the post-test mean score of the students using personalized learning mode is higher 3,485 points that students using non-personalized learning mode. 
Table 7. Statistical information for the paired-samples T-test of both learning modes under the students with the same pre-test score

\begin{tabular}{|l|l|r|r|r|r|}
\hline \multicolumn{2}{|l|}{} & \multicolumn{1}{c|}{ Mean } & N & Std. Deviation & $\begin{array}{c}\text { Std. Error } \\
\text { Mean }\end{array}$ \\
\hline Pair 1 & $\begin{array}{l}\text { Post_test_Score_of_non_personaliz } \\
\text { ed_learning_mode }\end{array}$ & 71,212 & 33 & 3,403 & 0,592 \\
\cline { 2 - 5 } & $\begin{array}{l}\text { Post_test_Score_of_personalized_ } \\
\text { learning_mode }\end{array}$ & 74,697 & 33 & 4,489 & 0,782 \\
\hline
\end{tabular}

Table 8. Result of paired-samples T-test of of both learning modes under the students with the same pre-test score

\begin{tabular}{|c|c|c|c|c|c|c|c|c|c|}
\hline \multicolumn{2}{|c|}{} & Mean & $\begin{array}{c}\text { Std. } \\
\text { Deviation }\end{array}$ & $\begin{array}{c}\text { Std. Error } \\
\text { Mean }\end{array}$ & $\begin{array}{c}95 \% \text { Confidence } \\
\text { Interval of the } \\
\text { Difference }\end{array}$ & t & df & $\begin{array}{c}\text { Sig. (2- } \\
\text { tailed) }\end{array}$ \\
\cline { 2 - 6 } Pair & $\begin{array}{c}\text { Post_test_Score_of_ } \\
\text { non_personalized } \\
\text { _learning_mode- } \\
\text { Post_test_Score_of_ } \\
\text { personalized_learnin } \\
\text { g_mode }\end{array}$ & $-3,424$ & 3,865 & 0,673 & $-4,795$ & $-2,054$ & $-5,089$ & 32 & 0,000 \\
\hline
\end{tabular}

\section{CONCLUSIONS}

This study proposes a personalized learning path generation scheme for individual students to support personalized webbased learning. The proposed scheme can simultaneously consider courseware difficulty level and the concept continuity of successive courseware according to the incorrect testing responses in a pre-test while implementing personalized courseware sequencing during learning processes. Compared to the non-personalized learning mode used in most web-based learning systems, experimental results indicated that the proposed personalized learning mode can precisely plan a personalized learning path for the courseware that a student has not acquired yet based on pre-test score and difficulty level of each learning unit, and moreover can promote student's learning effectiveness during learning processes. These results also indicated that personalized learning mode is superior to non-personalized learning mode in terms of learning efficiency. An important advantage is that the learning mode of curriculum sequencing recommendation customizes learning for those students who have very specific needs and not much time or patience to complete the topics they have to be learned.

\section{REFERENCES}

[1] Wang, Feng-Hsu. "On extracting recommendation knowledge for personalized web-based learning based on ant colony optimization with segmented-goal and meta- control strategies", Expert Systems with Applications, 39, 6446-6453, 2012.

[2] Yang, Y.J. \& Wua, C. “ An attribute-based ant colony system for adaptive learning object recommendation", Expert Systems with Applications 36, 3034-3047, 2009.

[3] Graf, S. "Adaptivity in learning management systems focusing on learning styles". Unpublished Doctoral Dissertation, Vienna University of Technology, Austria, 2007.

[4] Graf, S., \& Kinshuk. "Using cognitive traits for improving the detection of learning styles". In Workshop proceedings of the international conference on database and expert systems applications (DEXA 2010), Aug/Sep 2010 (pp. 74-78).

[5] Aguilar, G., \& Kaijiri, K. "Adaptive courseware generation of a web-based tutorial system". International Journal of Media, 34(3), 293-299, 2007.

[6] Prieto, M., \& García, F. "METHADIS: methodology for the design of adaptive hypermedia systems for learning based on learning and cognitive styles". In Proceedings of the sixth IEEE international conference on advanced learning technologies (ICALT'06) (pp. 1137-1138). The Netherlands: Kerkrade, 2006.

[7] Tseng, J. C. R., Chu, H. C., Hwang, G. J., \& Tsai, C. C. Development of an adaptive learning system with two sources of personalization information. Computers \& Education, 51(2), 776-786, 2008. 